\title{
"It's huge, in a way." Conflicting Stakeholder Priorities for Managing Hearing Impairment for People Living with Dementia in Residential Aged Care Facilities
}

Short title: Hearing impairment and dementia in RACFs

Anthea Bott ${ }^{\mathrm{ab} *} \mathrm{PhD}$, Carly Meyer ${ }^{\mathrm{ab}} \mathrm{PhD}$, Louise Hickson ${ }^{\mathrm{ab}} \mathrm{PhD}$, and

Nancy A. Pachana ${ }^{c} \mathrm{PhD}$

${ }^{a}$ The HEARing Cooperative Research Centre, Melbourne, Australia; ${ }^{b}$ School of Health and Rehabilitation Sciences, The University of Queensland, Brisbane, Australia;

${ }^{c}$ School of Psychology, The University of Queensland, Brisbane, Australia.

* corresponding author: Anthea Bott, School of Health and Rehabilitation Sciences, The University of Queensland, St Lucia, Queensland, Australia, 4067. E-mail:

anthea.bott@uq.net.au

ORCiDs: Anthea Bott: 0000-0003-1824-388X

Carly Meyer: 0000-0002-2268-3055

Louise Hickson: 0000-0001-6832-4173,

Nancy Pachana: 0000-0002-8927-4205

\section{Conflict of Interest}

The authors declare no conflict of interest.

\section{Funding}

The authors acknowledge the financial support of the HEARing CRC, established under the Australian Government's Cooperative Research Centres (CRC) Program. The CRC Program supports industry-led collaborations between industry, researchers and the community. 
"It's huge, in a way." Conflicting Stakeholder Priorities for Managing Hearing Impairment for People Living with Dementia in Residential Aged Care Facilities

\begin{abstract}
Objectives: The aims of this study were to a) explore the impact of hearing impairment on people living with dementia in residential aged care facilities (RACFs) and b) investigate management of hearing impairment for this population.

Methods: A descriptive qualitative approach, consisting of semi-structured interviews, was conducted with 23 participants across four stakeholder groups (audiologists, care staff, family members and individuals with dementia and hearing impairment living in RACFs).
\end{abstract}

Results: Thematic analysis revealed an overarching theme of "different priorities for managing hearing impairment" that emerged from the data. Audiologists and care staff prioritised different practices for managing hearing impairment: audiologists emphasised hearing aids and care staff emphasised communication strategies. Care staff also identified that current management of hearing impairment was sub-optimal as they do not prioritise managing it.

Conclusions: Residents with dementia and hearing impairment living in RACFs are not receiving optimal hearing management. Further research is required to understand the factors that influence this.

Clinical implications: Changes in practices of both care staff and audiologists are required to improve hearing impairment management for this population.

Key words: dementia, hearing impairment, qualitative, thematic analysis, residential aged care facility. 


\section{Introduction}

The co-occurrence of hearing impairment and dementia among people living in Residential Aged Care Facilities (RACFs) is high, with prevalence rates reported to be around 90\% (Hopper, Slaughter, Hodgetts, Ostevik, \& Ickert, 2016; Jupiter, 2012; Worrall, Hickson, \& Dodd, 1993). Several reasons explain the high concomitance of hearing impairment and dementia. First, prevalence of hearing impairment and dementia increase exponentially with age. Approximately 55\% of adults aged over 60 years and $80 \%$ of adults aged over 80 years have a bilateral hearing impairment (Lin, Niparko, \& Ferrucci, 2011); and approximately $10 \%$ of adults aged over 65 years and $43 \%$ of adults aged over 85 years have a dementia diagnosis (Australian Institute of Health and Welfare, 2012). Second, hearing impairment is independently associated with increased risk of dementia (Ford et al., 2018; Livingston et al., 2017; Loughrey, Kelly, Kelley, Brennan, \& Lawlor, 2018). For example, one prospective cohort study identified that, over an 11-year period, adults with a mild hearing impairment were almost twice as likely to develop dementia, and adults with a severe hearing impairment were nearly five times more likely to develop dementia, compared to adults without a hearing impairment (Lin, Metter, et al., 2011). Finally, population trends from 2011 showed that, compared to 2003, older adults in Australia are waiting longer before moving into RACFs (Australian Institute of Health and Welfare, 2014), and are therefore more likely to have multiple age-related health conditions such as dementia and hearing impairment when they do so. Despite the evidence for the commonality of hearing impairment among people living with dementia in RACFs, few empirical studies have considered the impact that hearing impairment has for this population.

Hearing impairment likely exacerbates the negative consequences of dementia on communication and quality of life for adults residing in RACFs (Hopper \& Hinton, 
2012; Hubbard, Mamo, \& Hopper, 2018; Pichora-Fuller, Dupuis, Reed, \& Lemke, 2013; Punch \& Horstmanshof, 2018), yet, in research, this has been investigated sparingly. Cohen-Mansfield et al. (2009) found that poorer hearing, as determined through a four-point scale where " 1 " represented those with highly impaired hearing and "4" represented those with adequate hearing, was associated with a higher refusal rate to engage in activities in 193 residents with dementia. However, this study did not consider whether the use of a hearing device altered residents' engagement in activities. Furthermore, a large Canadian cross-sectional study $(n=110,578)$ demonstrated that hearing impairment adds additional communication and functional difficulties to residents with cognitive impairment, compared to residents with cognitive impairment and no hearing impairment (Guthrie et al., 2018). Despite demonstrating the link between hearing impairment and greater disability in residents with dementia, these studies do not provide a comprehensive insight into how this impact is experienced by individuals or their caregivers.

Qualitative methods are used in audiology to examine participants' perceptions and experiences regarding hearing impairment (Knudsen et al., 2012) and have been applied to investigate the consequences of hearing impairment for people living with dementia in RACFs (Pryce \& Gooberman-Hill, 2012; Pryce \& Gooberman-Hill, 2013; Slaughter, Hopper, Ickert, \& Erin, 2014). Pryce and Gooberman-Hill (2012) conducted an ethnographic study and in-depth interviews with 18 people living with dementia in an RACF. Of these participants, eight were current hearing aid users, eight self-reported problems with their hearing but had not sought help, and two reported adequate hearing. Participants reported that factors within the RACF environment (noise and lack of social opportunity) placed restrictions upon their communication choices beyond those imposed by their hearing ability. Furthermore, a mixed-methods study conducted by 
Pryce and Gooberman-Hill (2013) - consisting of qualitative observations and interviews with 10 aged care staff, quantitative surveys with 65 aged care staff, and stakeholder meetings with 30 managers and senior aged care staff - found that aged care staff played an important role in supporting residents to access hearing services, yet aged care staff did not necessarily have the knowledge to facilitate this referral. Finally, Slaughter et al. (2014) conducted qualitative interviews with 12 aged care staff and found that they had trouble identifying a mild-to-moderate hearing impairment in adults with dementia, further highlighting the challenges of managing hearing impairment in this population. A limitation of these studies is that family caregiver perspectives were not explored.

Caregivers, both family and professional, play an important role in assisting residents living with dementia to manage their health conditions. People living with dementia can have difficulties expressing themselves and understanding information (Bayles, Tomoeda, \& Trosset, 1992), necessitating caregiver advocacy for their needs (Groen-van de Ven et al., 2016). Family involvement is also encouraged within audiology appointments (Meyer, Scarinci, Ryan, \& Hickson, 2015) and for people living with dementia who reside in RACFs (Stans, Dalemans, de Witte, \& Beurskens, 2013). To date, no single previous qualitative study has explored family caregivers or multiple stakeholder perspectives about the management and consequences of hearing impairment for people living with dementia within RACFs. Therefore, the aims of this study were to a) explore the impact of hearing impairment on people living with dementia in RACFs and b) investigate management of hearing impairment for this population. Because multiple stakeholders are involved in healthcare decision making for adults living with dementia in RACFs - audiologists, care staff, family members and individuals - we sought perspectives from representatives of these stakeholder groups. 


\section{Method}

\section{Study Design}

A descriptive qualitative study using one-on-one $(n=21)$ or dyadic $(n=2)$ in-depth, semi-structured interviews was conducted. Qualitative methods were chosen because they allowed for the exploration of key stakeholders' beliefs, experiences and perceptions (Knudsen et al., 2012). A descriptive qualitative approach was chosen as this approach has commonly been used to understand individuals' experiences in the health care sector (Kim, Sefcik, \& Bradway, 2017). The COnsolidated criteria for REporting Qualitative research (COREQ) checklist has been completed and is available as a supplementary file (see supplementary file 1). This study was approved by the University of Queensland Human Research Ethics Committee and Churches of Christ Care Ethics Committee and was conducted according to the National Statement on the Ethical Conduct of Human Research (National Health Medical Research Council \& Australian Vice-Chancellors' Committee, 2007).

\section{Participants}

Participants were recruited from audiology practices and RACFs in South West Queensland, Australia. A total of 23 participants were included in this study, consisting of four participant groups: audiologists $(n=5)$, care staff $(n=9)$, individuals with dementia and hearing impairment $(n=2)$, and family members $(n=7)$. These groups are described in the sections to follow.

Some participants were known to one another. The two individuals with dementia were related to two family member participants. There were instances where an audiologist discussed specifics about a care staff/family member who was also a participant in the study, or vice versa. Audiologists and care staff provided care 
to residents within the RACFs where the two individuals with dementia and hearing impairment resided. However, to our knowledge, the examples given during the interviews by audiologists and care staff did not relate to the two individuals with dementia who took part in the study. Audiologists.

Audiologists were recruited using convenience sampling. Audiologists were included if they had provided hearing services to an adult living with dementia and hearing impairment who resided in one of the three participating RACFs within the past 12 months. No additional exclusion criteria were applied. Audiologists were recruited through a two-step process. First, all audiology clinics within the geographical region were identified by searching the Australian Government Office of Hearing Services provider portal. Each audiology clinic was then contacted by the primary author to determine whether the clinic met the inclusion criteria, which six of these practices did. Second, audiologists from each clinic were invited to take part in the study. Five audiologists, three women and two men, participated in the study. One audiologist was in her 20s, three in their 30s and one in her 50s. Four audiologists had between five and 10 years' experience providing hearing services to adults living with dementia in RACFs, and one had between one and two years' experience. Three audiologists provided services directly within the RACF facility and two provided them for residents from their own clinics.

\section{Care staff.}

Care staff were recruited using purposeful sampling, specifically maximum variation sampling, to ensure variation in employment position within the RACF. For example, managers, registered nurses, and personal care workers were invited to take part in the study. Care staff were recruited directly from the RACF through the use of pamphlets and face-to-face conversations. Care staff were included if they were employed by the RACF and had provided care to residents living with dementia within the past 2 months. 
Recruitment of care staff was challenging. Care staff did not wish to participate in interviews outside of work hours. After several months of attempting to recruit care staff, we adjusted our approach. Interviews were shortened to 20 minutes so they could be conducted during work breaks.Nine care staff, seven women and two men, participated in the interviews, representing clinical care coordinators, registered nurses, endorsed enrolled nurses, lifestyle coordinators, and personal care workers.

\section{Individuals with dementia and hearing impairment.}

Individuals with dementia and hearing impairment were recruited using convenience sampling through a previous study that evaluated hearing in people living with dementia (Bott et al., 2020). The inclusion criteria for the present study were: assessed with questionable, mild, or moderate dementia severity according to the Clinical Dementia Rating Scale-Chronic Care Version (Marin et al., 2001); had a mild or greater hearing impairment (pure-tone average $>25 \mathrm{~dB}$ HL $0.5-4 \mathrm{kHz}$ in the better hearing ear); were able to converse in English; and had a family caregiver who could be present during the interviews. Family member presence was specified on the ethics approval and was considered important for helping to create a relaxed environment for the individual with dementia. Assessment of dementia serverity and hearing impairment was completed by the first author during a previous study (Bott et al., 2020). Sixteen participants were in the previous study, of which, four met the above inclusion criteria. Of these, two consented to take part in the study. The two participants, one male and one female, were both in their early 90s, were assessed to have moderate dementia, and used hearing aids.

\section{Family Members.}

Family members of an individual living with dementia and hearing impairment in an RACF were recruited using convenience sampling from a previous study (Bott et al., 
2020). Eight family members were invited to take part in this study, of which, seven consented. All family members were female and had an average age of $65( \pm 26)$ years. Family members were either a wife $(n=4)$ or daughter $(n=3)$ of the individual with dementia. Family members reported that their family member with dementia had various experiences with hearing aids; two currently used hearing aids, three previously used hearing aids, and one had never tried hearing aids.

\section{Procedure}

The study was conducted across three RACFs in South West Queensland between July 2017 and March 2018. A topic guide was developed and piloted with an audiologist and an RACF employee prior to participant interviews. This did not result in changes to the topic guide. Copies of the topic guide are provided as a supplementary file (see supplementary file 2). The interviews aimed to gain insight into the impact and management of hearing impairment for people living with dementia who reside in an RACF. Questions covered areas relating to: (1) the impact of hearing impairment for adults with dementia in RACFs; (2) how hearing impairment is managed for this population; and (3) how management of hearing impairment could be improved. Interviews were semi-structured in nature, meaning open-ended questions from the topic guide were asked; however, interviews were also flexible in nature and driven by participant responses. This approach allowed areas to be discussed by participants that may not have been considered by the research group (Given, 2016). The interviews were completed by the first author - an audiologists completing her $\mathrm{PhD}$ at the time of the study - either over the phone ( $n=3$ : an audiologist and two-family members) or face-to-face $(n=20)$ at a location convenient to the participant. All participants were unknown to the first author prior to taking part in the study. The goals of the study were explained to participants prior to participating. Interviews were one-off and ranged from 
10 to 67 minutes, and were audio recorded and transcribed by a professional transcription service. Transcripts were checked for accuracy by the first author before coding.

\section{Data analysis}

Transcripts were analysed via inductive thematic analysis (Braun \& Clarke, 2006).

Thematic analysis is a method for identifying, analysing, and reporting common themes among participants and contains six steps that were followed in the present study. Each step of thematic analysis was undertaken separately for the two research questions and was led by the first author (AB), an early career researcher. To enhance rigor and ensure transparency of findings, the second author $(\mathrm{CM})$, a speech pathologist and experienced qualitative researcher; and the third author $(\mathrm{LH})$, an audiologist with extensive experience conducting qualitative research covering a range of communication disorders, reviewed and reflected on each step of the analysis. The fourth author (NAP), a clinical psychologist with extensive experience researching ageing, dementia and RACFs, reviewed and agreed to the final report.

Initially, transcripts were read and re-read by the first author to become familiar with the data, and initial ideas were written down. Next, each transcript was systematically coded, creating an initial list of codes stored in Micrsoft Excel $^{\mathrm{TM}}$ Once all transcripts had been coded, the third step involved gathering the codes into potential themes, ensuring all data relevant to each potential theme was collated. The fourth step involved refining themes, whereby all potential themes were reviewed at the level of the coded data extracts and then against the entire data set for each participant group. This process resulted in the development of a thematic map. The fifth step, defining and naming themes, involved assigning names to each theme and ensuring each theme and 
category told a coherent story relating to the specific research question. The final step of thematic analysis involved producing the report, whereby extracts from the data were used to support the themes and categories relating to the research questions. A theme reflected central concepts constructed from the data and considered important in the context of the research questions. A category represented an element that related to the overarching theme. To enhance analytic rigor, peer checking was completed for steps two to six and discrepancies were resolved during team meetings. All authors agreed to the final report.

\section{Results}

Themes that emerged from the data for each research question are presented in Tables 1 to 5. An overview of each theme and associated categories are presented in the text below.

Two interrelated themes emerged in relation to the first research question: What is the impact of hearing impairment for people living with dementia who reside in aged care homes? These themes were: (1) far-reaching consequences to the individual; and (2) appropriate management of hearing impairment can be beneficial and important for people living with dementia.

\section{Theme 1: Far-Reaching Consequences to the Individual "It's actually huge in a way"}

The far-reaching consequences of hearing impairment on the individual were categorised as: (1) emotional consequences; (2) social consequences; (3) behavioural consequences; and (4) communication consequences (see Table 1). Emotional consequences reported by stakeholder groups to be associated with hearing impairment in people with dementia living in RACFs included frustration, grumpiness, distress, and 
feeling stupid. One care staff member summed up the emotional consequences by saying: "It's really going to affect them emotionally when they can't hear." Stakeholder groups also identified that consequences of hearing impairment affected residents' social interactions during activities and mealtimes, describing examples of loneliness, decreased engagement, avoidance, and confusion. Aged care staff identified that hearing impairment contributed to behavioural consequences for people living with dementia, and that these behaviours impacted residents' ability to receive care from nursing staff. Lastly, all stakeholder groups discussed the pervasive consequences that hearing impairment had for communication. Specifically, hearing impairment made residentstaff communication more difficult and affected residents' ability to follow caregiver conversations.

[Insert Table 1 around here]

\section{Theme 2: Appropriate Management of Hearing Impairment can be Beneficial and Important for People with Dementia}

The second theme that emerged from the participant data in relation to the impact of hearing impairment for people living with dementia in RACFs was the importance of and benefits associated with appropriately managing hearing impairment (see Table 2). Participants from all stakeholder groups discussed how addressing hearing impairment was important for the individual, describing that the effective use of hearing aids and/or communication strategies improved residents' mood, energy levels and engagement in conversations.

[Insert Table 2 around here]

One overarching theme emerged in relation to the second research question: How is hearing impairment managed for residents with dementia? The overarching 
theme was acknowledgement of different priorities for the management of hearing impairment in residents with dementia. Each stakeholder group emphasised different practices for managing hearing impairment, creating four categories under this overarching theme. The four categories were: (1) audiologists emphasised device management; (2) care staff emphasised communication strategies; (3) family members had mixed views on hearing aids and used communication strategies; and (4) individuals with dementia and hearing impairment had mixed views on the benefits of their hearing aids.

\section{Category 1: Audiologists Emphasised Device Management (n=5)}

For the management of hearing impairment, all audiologists prioritised hearing devices, specifically hearing aids (see Table 3). For example, an audiologist said "Well, obviously, if the client can't hear or is really struggling to hear, I would consider hearing aids first." Audiologists identified that hearing aid use and level of technology is influenced by the presence of dementia, highlighting that many people living with dementia were unable to manage their hearing aids. Audiologists also discussed using assistive listening devices (ALDs) to manage hearing impairment for this population; however, audiologists only considered ALDs when hearing aids were thought to be inappropriate, and expressed somewhat negative views about ALDs. Lastly, audiologists discussed provision of counselling and communication strategies to caregivers in place of or alongside hearing devices.

[Insert Table 3 around here]

\section{Category 2. Care Staff Emphasised using Communication Strategies (n=9)}

In contrast to audiologists, care staff emphasised using communication strategies to manage hearing impairment in residents with dementia (see Table 4). Care staff 
discussed strategies such as: moving closer to the individual; maintaining eye contact; and slowing down their speech to improve resident-caregiver communication. Care staff members also discussed using visual aids to facilitate communication, however identified that these were not always an available resource in the RACF. Care staff reported supporting management of hearing aids among residents, but acknowledged that hearing impairment was poorly managed for this population in that they did not tend to refer residents with dementia and hearing concerns to hearing services.

[Insert Table 4 around here]

\section{Category 3: Family members Emphasized a Person-Centered Approach (n=7)}

Family members presented mixed views on the benefits of hearing aids for managing hearing impairment in this population (see Table 5). Family members described individualised approaches for managing hearing impairment as well as the importance of shared decision making, thus they emphasize a person-centered approach. For example, some caregivers felt hearing aids were vital to their family member's communication and quality of life, yet others felt hearing aids were of no benefit, attributing communication problems to dementia rather than hearing impairment. Family members also discussed using multiple communication strategies to improve interactions and provided these strategies to care staff to use.

[Insert Table 5 around here]

\section{Category 4: Individuals with Dementia and Hearing Impairment had Mixed} Views on the Benefits of their Hearing aids $(n=2)$

The two individuals with dementia and hearing impairment who took part in the interviews both wore hearing aids and expressed unique perspectives on their hearing aids. One resident felt the benefit of their hearing aids were limited. "Oh, to a degree. 
But not real good. But sometimes they [hearing aid] could be alright." The other reported it took time to get used to his hearing aids "Early in the piece, it [hearing aid] wasn't that hot, but when I got used to it, it's pretty good."

\section{Discussion}

This study explored the impact and management of hearing impairment for people living with dementia in RACFs from the perspective of four stakeholder groups. The participants discussed the far-reaching consequences that hearing impairment has for people living with dementia, extending beyond resident-caregiver communication. Participants also identified that appropriately managing hearing impairment would be beneficial and important for residents living with dementia. This study found that stakeholder priorities for managing hearing impairment are different: audiologists emphasised hearing aids whereas care staff emphasised communication strategies. Additionally, care staff identified that current management of hearing impairment was sub-optimal, as they did not routinely refer residents with dementia and hearing concerns to hearing services. Therefore, to improve the management of hearing impairment and reduce the far-reaching consequences, modifications to both hearing and aged care services should occur.

All stakeholder groups discussed the far-reaching consequences that a hearing impairment has for people living with dementia in RACFs, which is largely consistent with other research conducted in this area (Punch \& Horstmanshof, 2018; Slaughter \& Bankes, 2007; Slaughter et al., 2014). In the present study, participants reported that hearing impairment interferes with communication and has psychosocial consequences; thus, hearing impairment is likely to impact residents' quality of life and ability to receive care. This finding is consistent with that of Slaughter and colleagues (2014) who 
identified that hearing impairment resulted in poorer quality of care and reduced quality of life of residents with dementia. Additionally, in the present study, the two individuals with dementia and hearing impairment who participated reported emotional consequences of their hearing impairment, feeling stupid when they misheard conversations. This finding is consistent with the findings reported by Pryce and Gooberman-Hill (2012) where some participants also described the pervasive psychosocial consequences of their hearing impairment.

Generally, participants in the present study felt it was both important and beneficial to manage hearing impairment in residents living with dementia. Participants discussed how the effective use of communication strategies or hearing aids improved communication interactions and residents' mood, and resulted in improved engagement in activities within the RACF. Again, this finding is consistent with previous research, highlighting the importance of treating hearing impairment to improve communication, social engagement, and quality of life of people living with dementia (Dawes, Wolski, Himmelsbach, Regan, \& Leroi, 2018; Hopper, 2007; Hubbard et al., 2018; Mamo et al., 2018; Pichora-Fuller et al., 2013). However, in the present study, audiologists and care staff emphasised different priorities for managing hearing impairment, and family members and individuals living with dementia and hearing impairment presented mixed views on the use of hearing aids. These juxtaposing practices and attitudes among key stakeholders are a new finding and may provide some insight into why hearing impairment is currently not well managed or prioritised for residents with dementia.

Hearing aids are the most commonly recommended option for managing hearing impairment and, accordingly, audiologists involved in the present study prioritised hearing aid fitting over other hearing rehabilitation options. However, there is limited high-level evidence demonstrating the benefits of hearing aids for older people living 
with dementia (Dawes et al., 2018; Mamo et al., 2018). Furthermore, emphasis on hearing aids is not compatible with many clinical guidelines. For example, the American Speech-Language-Hearing Association (ASHA) guidelines for the delivery of hearing services to people living in RACFs (including those with cognitive impairment) identifies that ALDs may be more appropriate for this population (American SpeechLanguage-Hearing Association, 1997). In the present study, only two audiologists discussed offering ALDs to manage hearing impairment for adults with dementia living in RACFs, and their views were somewhat negative, reporting that ALDs were old and bulky and that many residents did not like wearing them. This expressed perception is similar to findings reported by Jupiter (2016), who found most participants did not persist with the ALD because it was too bulky or they had difficulty learning how to use it.

Care staff who participated in this study emphasised the use of communication strategies (for example, using gestures or slowing down speech), as opposed to hearing devices, to best manage hearing impairment in adults with dementia. Evidence-based communication strategies have been recognised as effective in improving residentcaregiver communication interactions for people living with dementia (Conway \& Chenery, 2016; Eggenberger, Heimerl, \& Bennett, 2013; Sprangers, Dijkstra, \& Romijn-Luijten, 2015) and for assisting adults with hearing impairment and their caregivers (Hickson, Worrall, \& Scarinci, 2006). However, some of the communication strategies identified by caregivers in this study may not be the most effective for residents who have both a sensory and a cognitive communication impairment. Background noise interferes with communication and is particularly problematic within RACFs (Pryce \& Gooberman-Hill, 2012). Yet, in the present study, only one participant discussed how the environmental noise of the RACF may interfere with 
communication. This finding is consistent with that of Slaughter et al. (2014), who identified that communication strategies used by care staff may not be evidence-based for residents living with dementia. Therefore, care staff may benefit from receiving training on evidence-based communication strategies for adults living with dementia and hearing impairment in the context of an RACF setting. Examples of these include repeating or rephrasing the message, speaking face-to-face, and avoiding noisy, reverberant environments (Hopper \& Hinton, 2012). Additionally, external compensatory communication strategies, such as the use of memory books (Egan et al., 2010), also assist with comprehension for people living with dementia. These external strategies do not rely on intact hearing, and thus may be of additional importance for adults living with dementia and hearing impairment. Although care staff acknowledged the negative consequences of hearing impairment for residents living with dementia, they reported that they did not routinely refer these residents to hearing services. In the present study, care staff discussed various reasons for this, including: (1) hearing impairment is under-recognised among residents living with dementia; (2) hearing impairment is not a priority; and (3) care staff question the appropriateness of hearing aids for this population. These findings are largely consistent with other research groups who have identified that hearing impairment is under-recognised and not a priority for care staff (Adams-Wendling, Pimple, Adams, \& Titler, 2008; CohenMansfield \& Taylor, 2004a, 2004b; Crosbie et al., 2019; Pryce, Hall, LaplanteLévesque, \& Clark, 2016; Slaughter et al., 2014). Further exploration of why care staff do not routinely refer residents to hearing services should be explored in larger quantitative studies.

Care staff practice of non-referral may not wholly align with current dementia and care clinical guidelines. For example, in 2016, the Australian Government National 
Health and Medical Research Council supported the development of clinical practice guidelines and principles of care for people with dementia (Guideline Adaptation Committee, 2016). These guidelines stipulate that people with dementia should not be excluded from any health care services because of their diagnosis, whatever their age. Similarly, the Australian Aged Care Home Quality Standards state that residents of RACFs should receive ongoing needs assessment and receive suitable personal and clinical care (Aged Care Quality and Safety Commission, 2019). Moreover, a recent realist synthesis identified that care staff ability to appropriately manage hearing impairment for residents with dementia is influenced by whether they are given permission to manage it (Crosbie et al., 2019). Given the high prevalence and farreaching consequences of hearing impairment among residents with dementia, the provision of hearing services should be an essential part of this care and care staff should be supported and permitted to help residents manage hearing impairment.

In the present study, family members expressed views that aligned with personcentered care, including a preference for individualised and more holistic care and shared decision making. Hearing impairment management often requires a holistic approach, such as hearing aids used in conjunction with communication training and environmental modifications of the RACF environment (Pichora-Fuller et al., 2013; World Health Organization, 2001) and previous research groups have explored the outcomes of providing ALDs and communication training for people living with dementia in the community and their caregivers (Mamo et al., 2017). However, family members involved in the present study were unaware of device options other than hearing aids. Therefore, increasing family caregiver knowledge of all options available for treating hearing impairment may be an important step to achieving holistic hearing care. 


\section{Clinical Implications and Future Research Directions}

Findings from this study have clinical implications for hearing services and RACF services. First, care staff should arrange for all residents to have their hearing routinely screened. For this to be successful, audiology services should become integrated into aged care services and seen as an essential component of care rather than an adjunct (Lewsen \& Cashman, 1997). Second, audiologists should be mindful of their scope of practice, ensuring they offer residents choices for treating their hearing impairment and employ holistic approaches for hearing rehabilitation (World Health Organization, 2001). Third, some family members and care staff overlooked the impact of hearing impairment on communication, attributing problems solely to dementia. This perspective may at times be inaccurate. Family members and care stafff may benefit from education on the pervasive consequences that hearing impairment has on communication and overall well-being.

Managing hearing impairment for adults living with dementia and hearing impairment in RACFs requires collaboration from key stakeholders. In the present study, we identified audiologists, care staff, family members and individuals as key stakeholders. Other medical and allied health professionals may also be stakeholders depending on the setting. For example, in the United States, speech-language pathologists can also provide hearing screening, recommend communication and memory strategies, and may have more of a presence within RACFs than audiologists. Interdisciplinary collaboration may help to facilitate improved management of hearing impairment for this population.

The present study identified that improving the management of hearing impairment for RACF residents living with dementia requires behaviour change by audiologists and care staff. For example, audiologists involved in the present study 
discussed the limitations of hearing aids - that is, that many adults with dementia could not manage their hearing aids independently, that hearing aids were often lost or not working due to wax - yet, continued to prioritise this option. Additionally, care staff acknowledged that hearing impairment is not a priority and that they do not always know how to support a resident to manage their hearing aids nor use evidence-based communication strategies. The underlying reasons behind this pattern of behaviour are currently not known. As such, future research should consider utilising behaviour change frameworks (Coulson, Ferguson, Henshaw, \& Heffernan, 2016) to further explore this and other factors that influence hearing impairment management for people living with dementia who reside in RACFs.

\section{Limitations}

This research is limited by the small number of individuals living with dementia and hearing impairment who took part in the interviews, both of whom were assessed with moderate dementia severity and used hearing aids. It is important to include individuals' with dementia in qualitative research (Kitwood, 1997). However, only having two participants living with dementia obviously limits the applicability of findings to the broader population of people living with dementia who reside in RACFs. Future research should include individuals with dementia and hearing impairment who do and do not use hearing aids. It would be valuable to also include participants with a broader range of dementia severity. Such research could highlight important differences in individual needs and shape clinical practice. In addition, family members and some RACF staff who took part in the study may have also had hearing impairment, which could have influenced the findings. Future studies of a similar nature should consider screening hearing of all participant groups. While family members in the present study emphasized a person-centered approach for managing hearing impairment, it may not 
be appropriate to generalize these findings to family members outside of this study. In particular, given that country differences exist with regard to the implementation of person-centered care (Picker Institute Europe, 2016), family member perspectives may differ in different countries. Further research is needed to explore family member perspectives of managing hearing impairment in residents with dementia in countries other than Australia to more fully understand the generalizability of these findings.

\section{Conclusions}

The far-reaching consequences of hearing impairment on people living with dementia in RACFs was reported in the qualitative interviews, along with the need for appropriate management. However, different stakeholder priorities for managing hearing impairment - audiologists emphasising hearing aids and care staff emphasising communication strategies - suggest that changes to hearing services are required. To improve management of hearing impairment for this population, audiologists should adopt a more patient-centered approach, ensuring that they recommend all options available for managing hearing impairment, rather than emphasising hearing aids.

\section{Clinical implications bullet points}

- Hearing impairment has far-reaching consequences for residents with dementia, affecting mood, behaviour and communication.

- Hearing impairment is sub-optimally managed for this population.

- Changes in practices of both care staff and audiologists is required to improve hearing impairment management for adults living with dementia in RACFs. 


\section{Acknowledgements}

The authors would like to acknowledge the support of: Professor Robert Cowan and Dr Kathryn Havas in reviewing this manuscript; Churches of Christ Care for their support of this research project; and all participants who gave their time to take part in this project.

\section{References}

Adams-Wendling, L., Pimple, C., Adams, S., \& Titler, M. G. (2008). Nursing management of hearing impairment in nursing facility residents. Journal of Gerontological Nursing, 34(11), 9-17.

Aged Care Quality and Safety Commission. (2019). Guidance and resources for providers to support the Aged Care Quality Standards. Canberra, Australia: Australian Government

American Speech-Language-Hearing Association. (1997). Guidelines for audiology service delivery in nursing homes [guidelines]. ASHA Suppl, 39(2 Suppl 17), 1529. https://doi.org/10.1044/policy.GL1997-00004

Australian Institute of Health and Welfare. (2011). Residential aged care in Australia, 2009-10 : a statistical overview. Canberra: AIHW.

Australian Institute of Health and Welfare. (2012). Dementia in Australia. Cat. no. AGE 70. Canberra: AIHW.

Australian Institute of Health and Welfare. (2014). Patterns in use of aged care 2002-03 to 2010-11. Data linkage series no. 18. CSI 20. Canberra: AIHW.

Australian Institute of Health and Welfare. (2018). Older Australia at a glance. Cat. no: AGE 87. Retrieved from https://www.aihw.gov.au/reports/older-people/olderaustralia-at-a-glance/contents/health-functioning/burden-of-disease

Bayles, K. A., Tomoeda, C. K., \& Trosset, M. W. (1992). Relation of linguistic communication abilities of Alzheimer's patients to stage of disease. Brain and Language, 42(4), 454-472. https://doi.org/10.1016/0093-934X(92)90079-T

Bott, A., Hickson, L., Meyer, C., Bardy, F., Van Dun, B., \& Pachana, N. A. (2020). Is cortical automatic threshold estimation a feasible alternative for hearing threshold estimation with adults living with dementia? International Journal of 
Audiology, Advance online publication.

https://doi.org/10.1080/14992027.2020.1746976.

Braun, V., \& Clarke, V. (2006). Using thematic analysis in psychology. Qualitative Research in Psychology, 3(2), 77-101.

https://doi.org/10.1191/1478088706qp063oa

Cohen-Mansfield, J., Marx, M. S., Regier, N. G., \& Dakheel-Ali, M. (2009). The impact of personal characteristics on engagement in nursing home residents with dementia. International journal of Geriatric Psychiatry, 24(7), 755-763. https://doi.org/10.1002/gps.2192

Cohen-Mansfield, J., \& Taylor, J. W. (2004a). Hearing aid use in nursing homes. Part 1: Prevalence rates of hearing impairment and hearing aid use. Journal of the American Medical Directors Association, 5(5), 283-288.

Cohen-Mansfield, J., \& Taylor, J. W. (2004b). Hearing aid use in nursing homes. Part 2: Barriers to effective utilization of hearing AIDS. Journal of the American Medical Directors Association, 5(5), 289-296.

Conway, E. R., \& Chenery, H. J. (2016). Evaluating the MESSAGE Communication Strategies in Dementia training for use with community-based aged care staff working with people with dementia: A controlled pretest-post-test study. Journal of Clinical Nursing, 25(7-8), 1145-1155. https://doi.org/10.1111/jocn.13134

Coulson, N. S., Ferguson, M. A., Henshaw, H., \& Heffernan, E. (2016). Applying theories of health behaviour and change to hearing health research: Time for a new approach. International Journal of Audiology, 55, S99-S104. https://doi.org/10.3109/14992027.2016.1161851

Crosbie, B., Ferguson, M., Wong, G., Walker, D.-M., Vanhegan, S., \& Dening, T. (2019). Giving permission to care for people with dementia in residential homes: learning from a realist synthesis of hearing-related communication. $B M C$ Medicine, 17(1), 54. https://doi.org/10.1186/s12916-019-1286-9

Dawes, P., Wolski, L., Himmelsbach, I., Regan, J., \& Leroi, I. (2018). Interventions for hearing and vision impairment to improve outcomes for people with dementia: A scoping review. International Psychogeriatrics, 1-19. https://doi.org/10.1017/s1041610218000728

Egan, M., Bérubé, D., Racine, G., Leonard, C., \& Rochon, E. (2010). Methods to Enhance Verbal Communication between Individuals with Alzheimer's Disease and Their 
Formal and Informal Caregivers: A Systematic Review. International Journal of Alzheimer's Disease, 2010(2010), 12. https://doi.org/10.4061/2010/906818

Eggenberger, E., Heimerl, K., \& Bennett, M. I. (2013). Communication skills training in dementia care: A systematic review of effectiveness, training content, and didactic methods in different care settings. International Psychogeriatrics, 25(3), 345-358. https://doi.org/10.1017/S1041610212001664

Ford, A. H., Hankey, G. J., Yeap, B. B., Golledge, J., Flicker, L., \& Almeida, O. P. (2018). Hearing loss and the risk of dementia in later life. Maturitas, 112, 1-11. doi: https://doi.org/10.1016/j.maturitas.2018.03.004

Given, L. M. (2016). 100 questions (and answers) about qualitative research: Los Angeles : SAGE.

Groen-van de Ven, L., Smits, C., Span, M., Jukema, J., Coppoolse, K., de Lange, J., . . Vernooij-Dassen, M. (2016). The challenges of shared decision making in dementia care networks. International Psychogeriatrics, 1-15. https://doi.org/10.1017/s1041610216001381

Guideline Adaptation Committee. (2016). Clinical Practice Guildelines and Principles of Care for People with Dementia. Sydney: NHMRC Partnership Centre for Dealing with Cognitive and Related Functional Decline in Older People.

Guthrie, D. M., Davidson, J. G. S., Williams, N., Campos, J., Hunter, K., Mick, P., . . Wittich, W. (2018). Combined impairments in vision, hearing and cognition are associated with greater levels of functional and communication difficulties than cognitive impairment alone: Analysis of interRAI data for home care and longterm care recipients in Ontario. PLoS ONE, 13(2), e0192971. https://doi.org/10.1371/journal.pone.0192971

Hickson, L., Worrall, L., \& Scarinci, N. (2006). Measuring outcomes of a communication program for older people with hearing impairment using the International Outcome Inventory. International Journal of Audiology, 45(4), 238-246. https://doi.org/10.1080/14992020500429625

Hopper, T. (2007). The ICF and Dementia. Seminars in Speech and Language, 28(04), 273-282. https://doi.org/10.1055/s-2007-986524

Hopper, T., \& Hinton, P. (2012). Hearing Loss among Individuals with Dementia: Barriers and Facilitators to Care. Canadian Journal of Speech-Language Pathology and Audiology, 36(4), 302-313. 
Hopper, T., Slaughter, S. E., Hodgetts, B., Ostevik, A., \& Ickert, C. (2016). Hearing Loss and Cognitive-Communication Test Performance of Long-Term Care Residents With Dementia: Effects of Amplification. Journal of Speech, Language, and Hearing Research, 59(6), 1533-1542. https://doi.org/10.1044/2016_JSLHR-H-15-0135

Hubbard, H. I., Mamo, S. K., \& Hopper, T. (2018). Dementia and Hearing Loss: Interrelationships and Treatment Considerations. Seminars in Speech and Language, 39(3), 197-210. https://doi.org/10.1055/s-0038-1660779

Jupiter, T. (2012). Cognition and screening for hearing loss in nursing home residents. Journal of the American Medical Directors Association, 13(8), 744-747. https://doi.org/10.1016/j.jamda.2012.07.010

Jupiter, T. (2016). Does Hearing Assistive Technology Provide Benefit to Nursing Home Residents with Dementia? A Pilot Study. Journal of the Academy of Rehabilitative Audiology, 49, 34-39.

Kim, H., Sefcik, J. S., \& Bradway, C. (2017). Characteristics of Qualitative Descriptive Studies: A Systematic Review. Research in nursing \& health, 40(1), 23-42. https://doi.org/10.1002/nur.21768

Knudsen, L. V., Laplante-Levesque, A., Jones, L., Preminger, J. E., Nielsen, C., Lunner, T., ... Kramer, S. E. (2012). Conducting qualitative research in audiology: A tutorial. International Journal of Audiology, 2012, Vol.51(2), p.83-92, 51(2), 8392. https://doi.org/10.3109/14992027.2011.606283

Lewsen, B. J., \& Cashman, M. (1997). Hearing aids and assistive listening devices in long-term care. Journal of Speech-Language Pathology \& Audiology, 21(3), 149-152 144p.

Lin, F. R., Metter, E. J., O'Brien, R. J., Resnick, S. M., Zonderman, A. B., \& Ferrucci, L. (2011). Hearing loss and incident dementia. Archives of Neurology, 68(2), 214-220. https://doi.org/10.1001/archneurol.2010.362

Lin, F. R., Niparko, J. K., \& Ferrucci, L. (2011). Hearing loss prevalence in the United States. Archives of Internal Medicine, 171(20), 1851-1852. https://doi.org/10.1001/archinternmed.2011.506

Livingston, G., Sommerlad, A., Orgeta, V., Costafreda, S. G., Huntley, J., Ames, D., . . . Mukadam, N. (2017). Dementia prevention, intervention, and care. The Lancet, 390(10113), 2673-2734. https://doi.org/10.1016/S0140-6736(17)31363-6 
Loughrey, D. G., Kelly, M. E., Kelley, G. A., Brennan, S., \& Lawlor, B. A. (2018). Association of age-related hearing loss with cognitive function, cognitive impairment, and dementia a systematic review and meta-analysis. JAMA Otolaryngology - Head and Neck Surgery, 144(2), 115-126. https://doi.org/10.1001/jamaoto.2017.2513

Mamo, S. K., Nirmalasari, O., Nieman, C. L., McNabney, M. K., Simpson, A., Oh, E. S., \& Lin, F. R. (2017). Hearing Care Intervention for Persons with Dementia: A Pilot Study. American Journal of Geriatric Psychiatry, 25(1), 91-101. https://doi.org/10.1016/j.jagp.2016.08.019

Mamo, S. K., Reed, N. S., Price, C., Occhipinti, D., Pletnikova, A., Lin, F. R., \& Oh, E. S. (2018). Hearing Loss Treatment in Older Adults With Cognitive Impairment: A Systematic Review. Journal of Speech, Language, and Hearing Research : JSLHR, 61(10), 2589-2603. https://doi.org/10.1044/2018_JSLHR-H-18-0077

Marin, D. B., Flynn, S., Mare, M., Lantz, M., Hsu, M., Laurans, M., . . Mohs, R. C. (2001). Reliability and validity of a chronic care facility adaptation of the Clinical Dementia Rating scale. International Journal of Geriatric Psychiatry, 16(8), 745-750. https://doi.org/10.1002/gps.385

Meyer, C., Scarinci, N., Ryan, B., \& Hickson, L. (2015). "This Is a partnership between all of us": Audiologists' perceptions of family member involvement in hearing rehabilitation. American Journal of Audiology, 24(4), 536-548. https://doi.org/10.1044/2015_AJA-15-0026

National Health Medical Research Council \& Australian Vice-Chancellors' Committee. (2007). National statement on ethical conduct in human research Canberra National Health and Medical Research Council.

O’Brien, C. B., Harris, B. I., Beckman, J. T., Reed, A. D., \& Cook, A. D. (2014). Standards for reporting qualitative research: a synthesis of recommendations. Academic Medicine, 89(9), 1245-1251. https://doi.org/10.1097/ACM.0000000000000388

Pichora-Fuller, M. K., Dupuis, K., Reed, M., \& Lemke, U. (2013). Helping older people with cognitive decline communicate: Hearing aids as part of a broader rehabilitation approach. Seminars in Hearing, 34(4), 308-330. https://doi.org/10.1055/s-0033-1356643 
Picker Institute Europe. (2016). Person-centred care in Europe: a cross-country comparison of health system performance, strategies and structures. Picker Institute Europe, Oxford, England. Accessed online https://www.picker.org/wpcontent/uploads/2016/02/12-02-16-Policy-briefing-on-patient-centred-care-inEurope.pdf

Pryce, H., \& Gooberman-Hill, R. (2012). 'There's a hell of a noise': living with a hearing loss in residential care. Age Ageing, 41(1), 40-46. https://doi.org/10.1093/ageing/afr112

Pryce, H., \& Gooberman-Hill, R. (2013). Foundations of an intervention package to improve communication in residential care settings: A mixed methods study. Hearing, Balance and Communication, 11(1), 30-38.

https://doi.org/10.3109/21695717.2012.756224

Pryce, H., Hall, A., Laplante-Lévesque, A., \& Clark, E. (2016). A qualitative investigation of decision making during help-seeking for adult hearing loss. International Journal of Audiology, 55(11), 658. https://doi.org/10.1080/14992027.2016.1202455

Punch, R., \& Horstmanshof, L. (2018). Hearing loss and its impact on residents in long term care facilities: A systematic review of literature. Geriatric Nursing. https://doi.org/10.1016/j.gerinurse.2018.07.006

Slaughter, S. E., \& Bankes, J. (2007). The Functional Transitions Model: Maximizing ability in the context of progressive disability associated with Alzheimer's disease. Canadian Journal on Aging, 26(1), 39-47. https://doi.org/10.3138/Q62V-1558-4653-P0HX

Slaughter, S. E., Hopper, T., Ickert, C., \& Erin, D. F. (2014). Identification of hearing loss among residents with dementia: perceptions of health care aides. Geriatric Nursing, 35(6), 434-440. https://doi.org/10.1016/j.gerinurse.2014.07.001

Sprangers, S., Dijkstra, K., \& Romijn-Luijten, A. (2015). Communication skills training in a nursing home: Effects of a brief intervention on residents and nursing aides. Clinical Interventions in Aging, 10, 311-319. https://doi.org/10.2147/cia.s73053

Stans, S. E. A., Dalemans, R., de Witte, L., \& Beurskens, A. (2013). Challenges in the communication between 'communication vulnerable' people and their social environment: An exploratory qualitative study. Patient Education and Counseling, 92(3), 302-312. https://doi.org/10.1016/j.pec.2013.05.021 
World Health Organization. (2001). International classification of functioning, disability and health : ICF. Geneva: World Health Organization.

World Health Organization. (2019). Facts about deafness. Accessed online 9 October 2019. who.int/deafness/facts/en/

Worrall, L., Hickson, L., \& Dodd, B. (1993). Screening for communication impairment in nursing homes and hostels. Australian Journal of Human Communication Disorders, 21(2), 53-64. 
Table 1. Overview of Categories, Codes and Example Quotes for Theme 1 "FarReaching Consequences to the Individual"

Table 2. Overview of Categories, Codes and Example Quotes for Theme 2 "Appropriate Management of Hearing Impairment is Beneficial and Important for People living with Dementia"

Table 3. Overview of Sub-Categories, Codes and Example Quotes for Category 1 "Audiologists Emphasized Hearing Aids"

Table 4. Overview of Sub-Categories, Codes and Example Quotes for Category 2 " Care Staff Emphasised Using Communication Strategies"

Table 5. Overview of Sub-Categories, Codes and Example Quotes for Category 3 "Family Members Emphasized a Person-Centered Approach" 
Table 1. Overview of Categories, Codes and Example Quotes for Theme 1 "Far-Reaching Consequences to the Individual"

\begin{tabular}{|c|c|c|}
\hline Categories & Example codes & Example participant quotes \\
\hline \multirow[t]{4}{*}{$\begin{array}{l}\text { Emotional } \\
\text { consequences }\end{array}$} & Frustration & $\begin{array}{l}\text { They [PWD] probably have the feeling but when they can't hear what somebody is } \\
\text { trying to say to do or things like that. It's really frustrating as well. (CS) }\end{array}$ \\
\hline & Grumpiness & $\begin{array}{l}\text { I've seen other people do it now, even his daughter, when they approach him from } \\
\text { his left side he would also get cranky and yell "I can't hear you. What do you want?" } \\
\text { just grumpy responses. (CS) }\end{array}$ \\
\hline & Distressed & $\begin{array}{l}\text { Those sort of misunderstandings [not hearing] can also distress a person with } \\
\text { dementia. (CS) }\end{array}$ \\
\hline & Feel stupid & I just take it that it's just me stupid, not listening properly. (PWD) \\
\hline \multirow[t]{4}{*}{ Social consequences } & Feel lonely & $\begin{array}{l}\text { I guess with the hearing impaired or even lost their hearing, they should be... I guess } \\
\text { that they would feel very, very lonely. (CS) }\end{array}$ \\
\hline & Avoid activities & $\begin{array}{l}\text { And it's hard for him. And he's not doing activities in there like he used to because he } \\
\text { has that feeling of, "oh I can't hear people." (FAM) }\end{array}$ \\
\hline & Confused during activities & At times, it $[\mathrm{HI}]$ probably creates a little bit of confusion. (CS) \\
\hline & $\begin{array}{l}\text { Communication partners avoid } \\
\text { talking to PWD }\end{array}$ & $\begin{array}{l}\text { If they (aged care staff) don't understand him or he can't understand them, I think } \\
\text { they just walk out. (FAM) }\end{array}$ \\
\hline \multirow[t]{2}{*}{$\begin{array}{l}\text { Behavioural } \\
\text { consequences }\end{array}$} & Maladaptive behaviours & $\begin{array}{l}\text { If you can't hear what other people are saying, then obviously you would be } \\
\text { distressed, anxious, and because of dementia you are not able to express that the } \\
\text { right way, so that's why you have maladaptive behaviours. (CS) }\end{array}$ \\
\hline & Defensive behaviours & $\begin{array}{l}\text { I think one or two of them tried to undress him because they were saying it's time for } \\
\text { a shower or whatever and then he got quite defensive when they started trying to } \\
\text { undress him. I think that was all part of the accents, his hearing loss, and his }\end{array}$ \\
\hline
\end{tabular}


dementia that just about ... If he could have heard better that often would have overcome. (FAM)

Consequences of HI Communication is more on communication

\section{difficult}

Emotional responses
Very bad. I find it [talking to husband] impossible. (FAM)

The big point is that I get annoyed, and then that makes it worse, because then I can hear less. (IND)

Unable to follow conversations They are not able to follow conversation. (AUD)

Unable to hear conversations

Biggest complaint we get is in the dining room, just that they are not able to hear what people are saying. (AUD)

When somebody is deaf and you're trying to have an intimate conversation with someone you lose a lot of the intimacy and you lose a lot of the privacy. (CS)

Note: $C S=$ Care staff; $A U D=$ Audiologist $F A M=$ family member $; H I=$ hearing impairment $;$ IND = Indiviual living with dementia and

hearing impairment; $P W D=$ person living with dementia. 
Table 2. Overview of Categories, Codes and Example Quotes for Theme 2 "Appropriate Management of Hearing Impairment is Beneficial and Important for People living with Dementia"

\section{Codes}

Addressing hearing is important to the individual

Using hearing aids effectively improves communication

Using hearing aids effectively helps residents engage

Using hearing aids effectively reduces fatigue in residents with dementia

Using effective communication strategies improves conversations and residents' mood

Effective communication is part of a person's dignity

\section{Example participant quotes}

Absolutely important! He doesn't... if he doesn't hear he doesn't know what's going on. That's the world to him. (FAM)

So, once he got wearing those (hearing aids), the staff members all commented on how his dementia seemed to be a lot better. Purely because he could respond now. (AUD)

The patient or client themselves can engage a bit more (AUD) discussing outcomes of HA fitting.

They're [PWD] not as tired. (AUD) discussing outcomes of HA fitting.

If you come over to him gently on the other side, his right hand side of his body speaking to that ear I just found that was like opening a door. He could hear what I was saying, he smiled and we started talking and I sat down near him. (CS)

Well it's important because I think it's part of the person's dignity, it's kind of wrapped up in the dignity of communicating well with somebody. (CS)

Note: $C S=$ care staff; $A U D=$ audiologist $; F A M=$ family member $; H A=$ hearing aid; $P W D=$ person living with dementia 
Table 3. Overview of Sub-Categories, Codes and Example Quotes for Category 1 "Audiologists Emphasized Hearing Aids"

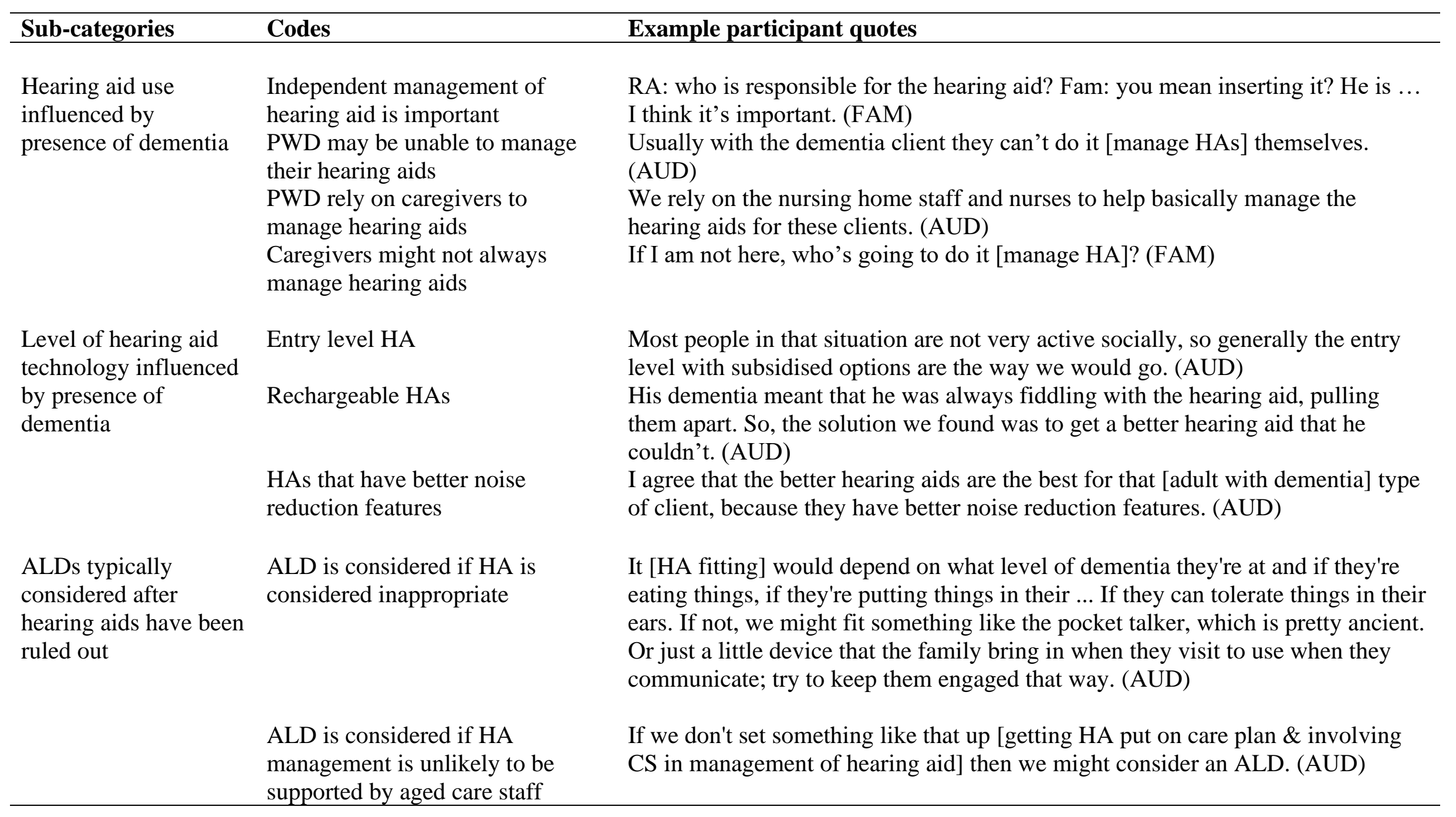


ALDs work quite well

ALDs aren’t ideal

Counselling and communication strategies provided to caregivers in place of or along side devices
You know, I've fit quite a few of those, it's like a pocket talker. It's an assisted device that they put on a headphone and just use it when they have visitors, and they seem to work quite well. (AUD)

Obviously, it's [ALD] not an ideal option for a lot of people that don't like the idea of wearing some big, chunky earphones for most of the day. (AUD)

Audiologists provides counselling and communication strategies in place of HAs to caregivers Counselling is important in hearing rehabilitation for people with dementia
I wouldn't always recommend a hearing aid or even a hearing device. For example, I'd focus more on the carer, because they're struggling a lot, and just ways for them to engage their partner better. (AUD)

Someone with dementia I feel like that is even more important rehabilitation side of it, the counselling side of it is even more important. (AUD)

Note: $C S=$ care staff; $A L D=$ assistive listening device; $A U D=$ audiologist $; F A M=$ family member; HA = hearing aid; HI = hearing impairment; IND = individual with dementia and hearing impairment; PWD = person living with dementia; 
Table 4. Overview of Sub-Categories, Codes and Example Quotes for Category 2 " Care Staff Emphasised Using Communication Strategies"

\begin{tabular}{|c|c|c|}
\hline Sub-categories & Codes & Example participant quotes \\
\hline \multirow{7}{*}{$\begin{array}{l}\text { CS use multiple } \\
\text { communication } \\
\text { strategies to overcome } \\
\text { the impact of HI }\end{array}$} & $\begin{array}{l}\text { Use multiple communication } \\
\text { strategies }\end{array}$ & $\begin{array}{l}\text { So, it really comes down to clear pronunciation, not yelling at them, but speaking } \\
\text { clearly, definite eye contact, and definite body language... use of if needed, } \\
\text { written word. (CS) }\end{array}$ \\
\hline & Speak to the better ear & If they've got one ear better than the other, choosing that side to speak to. (CS) \\
\hline & $\begin{array}{l}\text { Use gestures/body language/ } \\
\text { demonstrate }\end{array}$ & All the hand gestures and things seem to help. (CS) \\
\hline & Slow down / simplify speech & I tend to slow down and simplify what I am saying. (CS) \\
\hline & Maintain eye contact & $\begin{array}{l}\text { Well, usually just make sure they've got eye contact if they can. } \\
\text { (CS) }\end{array}$ \\
\hline & Clarify & $\begin{array}{l}\text { And if necessary sometimes, approach the resident and clarify that one on one. } \\
\text { (CS) }\end{array}$ \\
\hline & Move closer & I try to move a little closer. (CS) \\
\hline \multirow{3}{*}{$\begin{array}{l}\text { CS use visual aids to } \\
\text { overcome consequences } \\
\text { from HI }\end{array}$} & Use visual aids & I think we should always have visual aids. (CS) \\
\hline & Write things down & Another thing that sometimes helped, too, is to write things down. (CS) \\
\hline & $\begin{array}{l}\text { RACFs don't always have } \\
\text { visual resources for staff to use }\end{array}$ & $\begin{array}{l}\text { I think we should always have visual aids. I must admit, finding or trying to ... } \\
\text { Yeah, pretty much finding anything in an age care facility that has actual visual } \\
\text { and printed off and labelled, you know is very rare. (CS) }\end{array}$ \\
\hline \multirow{2}{*}{$\begin{array}{l}\text { CS support residents } \\
\text { who have HAs to wear } \\
\text { them }\end{array}$} & CS manage HAs & $\begin{array}{l}\text { Regularly upkeeping the hearing aids is really important. Changing the batteries } \\
\text { on a regular basis to making sure they're clean, that they're functioning well. (CS) }\end{array}$ \\
\hline & CS has HA management plan & $\begin{array}{l}\text { But how we are managing it here, is that we keep them [HA] in their case and } \\
\text { kept in the medication trolley. That's what I've implemented here, similar to what } \\
\text { I implemented at the other place, because it's very costly. So, I make sure that the }\end{array}$ \\
\hline
\end{tabular}


$\mathrm{RN}$ puts the hearing aids on in the morning, because it's on the medication trolley. The evening shift RN, before going out ... During their 8:00 medication rounds at night, they take the hearing aid off and put it back in the trolley. (CS)

CS identified that $\mathrm{HI}$ is sub-optimally managed for residents with dementia
HI isn't managed for residents with dementia

HI is overlooked

CS don't realise PWD isn't wearing HA when talking to them

CS don't refer PWD and hearing concerns to hearing services.
I couldn't say that it is particularly managed. (CS)

It's really hard because sometimes its just the natural progression that you don't always see that it could be that [HI], you just think it's part of dementia so it's probably skipped over quite a bit. (CS)

You can talk to them but not realising that they don't have their hearing aid in there. (CS)

I must admit, I have never seen that [refer to hearing services] happen. (CS)

Note: $C S=$ aged care staff, $H I=$ hearing impairment; $P W D=$ person living with dementia; $H A=$ hearing aid; RACFs $=$ Residential aged care facility; $R N=$ Registered Nurse 
Table 5. Overview of Sub-Categories, Codes and Example Quotes for Category 3 "Family Members Emphasized a Person-Centered Approach"

\begin{tabular}{|c|c|c|}
\hline Sub-categories & Codes & Example participant quotes \\
\hline \multirow[t]{3}{*}{ HA of benefit to PWD } & $\begin{array}{l}\text { Using HAs improves } \\
\text { communication }\end{array}$ & He doesn't hear anything if he doesn't have his hearing aid in. (FAM) \\
\hline & $\begin{array}{l}\text { HA helps PWD hear } \\
\text { instructions, which is important } \\
\text { to them }\end{array}$ & $\begin{array}{l}\text { I know that I have to be on track [changing HA batteries] so that she's } \\
\text { comfortable up here and can hear instructions because that's really important to } \\
\text { her. (FAM) }\end{array}$ \\
\hline & $\begin{array}{l}\text { Family support PWD to } \\
\text { manage their HA in the RACF }\end{array}$ & $\begin{array}{l}\text { I leave notes on the near the HA box. Gradually staff has probably passed it onto } \\
\text { new staff to say that her HAs have to come out at night and to open the battery } \\
\text { case so that they're disconnected. (FAM) }\end{array}$ \\
\hline \multirow[t]{3}{*}{$\begin{array}{l}\text { HAs aren't of benefit to } \\
\text { PWD }\end{array}$} & $\begin{array}{l}\text { Communication problem is } \\
\text { from dementia not HI }\end{array}$ & $\begin{array}{l}\text { I don't honestly think it is because of his hearing. I think it's because of his } \\
\text { dementia ... He might call a pen a rock or something, just something that doesn't } \\
\text { even relate to it. But, that's to do with the dementia, not the hearing. (FAM) }\end{array}$ \\
\hline & PWD doesn't want HAs & $\begin{array}{l}\text { When we've said before, earlier on, "would you like to go somewhere to see if } \\
\text { they can put a hearing aid in his good ear?" he said, "Oh no, just no, no. Don't } \\
\text { worry." (FAM) }\end{array}$ \\
\hline & $\begin{array}{l}\text { HAs are no longer appropriate } \\
\text { due to dementia progression }\end{array}$ & $\begin{array}{l}\text { Well, with mum and dad. There just came a time where HA was of no use, really. } \\
\text { Dad couldn't manage it, mum can't. (FAM) }\end{array}$ \\
\hline \multirow{4}{*}{$\begin{array}{l}\text { Families use } \\
\text { communication } \\
\text { strategies }\end{array}$} & Speak at family member & $\begin{array}{l}\text { I just try to be in the right position and try and speak directly at her and all that } \\
\text { sort of thing. (FAM) }\end{array}$ \\
\hline & Get close to family member & $\begin{array}{l}\text { You've just go to remember to try and stand near him, closer, and see your face } \\
\text { where he's watching what you're saying. (FAM) }\end{array}$ \\
\hline & Speak louder & So I would have to speak louder. That's all I did to compensate most of it. (FAM) \\
\hline & Repeat & I sometimes have to repeat a few things. (FAM) \\
\hline
\end{tabular}


Family provide communication I leave notes and I tell staff, and if I'm there and they're speaking to her, and I can strategies to CS tell Mum's not picking up the conversation, I just say, "You'll have to speak a bit louder," or "Come closer." (FAM)

Note: $H A=$ hearing aid, $P W D=$ person living with dementia; $F A M=$ family caregiver; $R A C F=$ Residential aged care facility; $C S=$ care staff; $H I=$ hearing impairment . 